\title{
BTEX concentrations in the atmosphere of the metropolitan area of Campinas (São Paulo, Brazil)
}

\author{
A. C. Ueda \& E. Tomaz \\ School of Chemical Engineering, State University of Campinas, \\ UNICAMP, Brazil
}

\begin{abstract}
Benzene, toluene, ethylbenzene and xylenes (BTEX) are hydrocarbons present in fossil fuels and, consequently, are also present in fuel combustion emissions, as toxic organic volatile compounds. Concentrations of these compounds found in the atmosphere of urban regions are indicative of vehicular pollution. In this work were studied BTEX atmospheric concentrations from five sites of metropolitan area of Campinas (São Paulo, Brazil), which have different characteristics: (1) suburban site; (2) downtown site; (3) urban site A; (4) urban site $\mathrm{B}$; (5) industrial. The most abundant compound found in all sites was toluene $\left(2.4-10 \mu \mathrm{g} \mathrm{m}^{-3}\right)$. B/T ratio was used to study predominance of vehicular emissions and $\mathrm{X} / \mathrm{E}$ indicates the distance from the site to the sources due to different photochemical reactivity of the compounds. It was possible to observe that sites away from the urban region and located in the predominant wind direction have lower concentration of BTEX as well as lower X/E ratios, indicating that pollution is due to transport emissions.

Keywords: atmospheric pollution, BTEX (benzene, toluene, ethylbenzene, xylenes), urban region, vehicular emissions, intensity of traffic, photochemical reaction, $X / E$ ratio, $B / T$ ratio, passive sampling, gas chromatography.
\end{abstract}

\section{Introduction}

Atmospheric emissions of a variety of gaseous pollutants are of great concern, mainly in urban areas. Some compounds, such as BTEX, are precursors of ground level ozone and are also harmful to human health. Benzene is known for its carcinogenic effect [1] and xylenes' oxidation products may be toxic or 
mutagenic, such as aromatic aldehydes and secondary organic aerosols [2]. BTEX are characteristic of fossil emissions and are reported as indicators of intense vehicular activity, corresponding to $60 \%$ of total non-methane VOC [3].

Metropolitan area of Campinas (São Paulo, Brazil) is located northwest of São Paulo city and is formed by 19 cities with a population of 2,797,137 inhabitants, $27,079 \mathrm{~km}^{2}$ and fleet equals to $1,425,125$ vehicles. The region is surrounded by important highways and has also an international airport, Viracopos. The industrial sector is also privileged with several companies, such as: pharmaceutical, automotive, textile, food and petrochemical industries.

The main objectives of this work were to study BTEX concentrations and proportions, as $\mathrm{B} / \mathrm{T}$ and $\mathrm{X} / \mathrm{E}$ ratios, as indicatives of dominant pollution sources. $\mathrm{B} / \mathrm{T}$ ratio was studied in many cities around the world and observed values between 0.2 and 0.5 were found in sites with vehicular pollution predominance [4]. $\mathrm{X} / \mathrm{E}$ ratio, instead, is based on different photochemical reactivity of xylenes and ethylbenzene (xylenes are more reactive than ethylbenzene). Therefore, higher ratios give higher xylenes concentrations and the plume is considered a fresh one, i.e., near emission sources [2].

\section{Experimental}

\subsection{Materials}

Hydrocarbons liquid standards were used to produce calibration curves. Benzene, ethylbenzene and o-xylene were purchased from Merck Schuchardt OHG (purity $>99 \%$ ), toluene was from Tedia (purity $>99.8 \%$ ), and $\mathrm{m}$ and $\mathrm{p}$ xylenes from Acros Organics (purity 99\%). Methyl alcohol (Merck KGaA) was used as solvent to construction of the curves.

Samples were collected into stainless steel tubes (Supelco) filled with Tenax TA. During sampling period aluminum caps with protection sieve and clips were used to prevent from insects and to fix the tubes, respectively.

Sample analysis were performed by thermal desorption (Automatic Thermal Desorption System ATD 400, Perkin Elmer) followed by gas chromatography (AutoSystem XL Gas Chromatograph, Perkin Elmer) with flame ionization detector. Capillary column for gas chromatography was NST-01 (60 m length, $0.25 \mathrm{~mm}$ inside diameter and $0.20 \mu \mathrm{m}$ dimethyl polysiloxane film thickness) purchased from Nano Separation Technologies (NST).

\subsection{Methods}

BTEX were sampled by passive method with period of exposition of ten days. After sampling, tubes were conditioned and analyzed in the same day. Sample analysis begins with two-step thermal desorption, where firstly the compounds are desorbed from the sample tube and are adsorbed into a cold trap during desorption time; then, the second desorption occurs from the trap directly to the column, where compounds will be analyzed. Tables 1 and 2 present the main parameters of thermal desorption and analysis by gas chromatography. 
Table 1: Desorption system parameters for thermal desorption and gas chromatography analysis.

\begin{tabular}{cc|cc}
\hline Parameter & Value & Parameter & Value \\
\hline Line temperature & $205^{\circ} \mathrm{C}$ & System pressure & $20 \mathrm{psi}$ \\
Oven temperature & $300^{\circ} \mathrm{C}$ & Inlet Split & $45 \mathrm{ml} \mathrm{min}^{-1}$ \\
Desorption time & $15 \mathrm{~min}$ & Outlet Split & $25 \mathrm{ml} \mathrm{min}^{-1}$ \\
Valve temperature & $205^{\circ} \mathrm{C}$ & Desorb Flow & $60 \mathrm{ml} \mathrm{min}^{-1}$ \\
\hline
\end{tabular}

Table 2: $\quad$ Gas chromatography analysis parameters.

\begin{tabular}{cccc}
\hline & Rate $\left({ }^{\circ} \mathrm{C} \min ^{-1}\right)$ & $\mathrm{T}\left({ }^{\circ} \mathrm{C}\right)$ & Hold $(\min )$ \\
\hline Initial & - & 35 & 13 \\
Step 1 & 2,0 & 60 & 10 \\
Step 2 & 1,5 & 80 & 5 \\
Step 3 & 7,0 & 100 & 10 \\
\hline
\end{tabular}

Five different sites within the metropolitan area of Campinas were chosen based on the main wind direction in the region:

1) Suburban site (SU) - sample was taken in a location outside the urban area of Campinas, near an extensive green area;

2) Downtown site (DT) - sample was taken in front of a residential building near Campinas downtown, with great intensity of traffic;

3) Urban site A (UA) - sample taken in Campinas, in a mainly residential neighborhood, far from downtown city and with low intense of traffic;

4) Urban site B (UB) - taken in Paulínia, $10 \mathrm{~km}$ far from to Campinas, in a region of high intense of traffic, far from downtown and located in the main wind direction of the region (may receive pollution from Campinas);

5) Industrial site (IN) - sample taken inside an oil refinery area; according to the dispersion study in the local of greater influence of these industrial emissions.

\section{Results and discussion}

Localization of sampling sites is presented in Figure 1 and geographical coordinates (UTM) are presented in Table 3.

Table 3: $\quad$ Coordinates from sampling sites.

\begin{tabular}{|c|c|c|c|}
\hline Site & City & \multicolumn{2}{|c|}{ Coordinates (UTM) } \\
\hline SU & Campinas - SP & $300,347.72 \mathrm{E}$ & $7,467,775.21 \mathrm{~S}$ \\
\hline DT & Campinas - SP & $288,606.76 \mathrm{E}$ & $7,466,289.50 \mathrm{~S}$ \\
\hline UA & Campinas - SP & $290,850.36 \mathrm{E}$ & $7,470,140.09 \mathrm{~S}$ \\
\hline UB & Paulínia - SP & $277,866.86 \mathrm{E}$ & $7,478,325.18 \mathrm{~S}$ \\
\hline IN & Paulínia - SP & $280,532.57 \mathrm{E}$ & $7,485,671.14 \mathrm{~S}$ \\
\hline
\end{tabular}




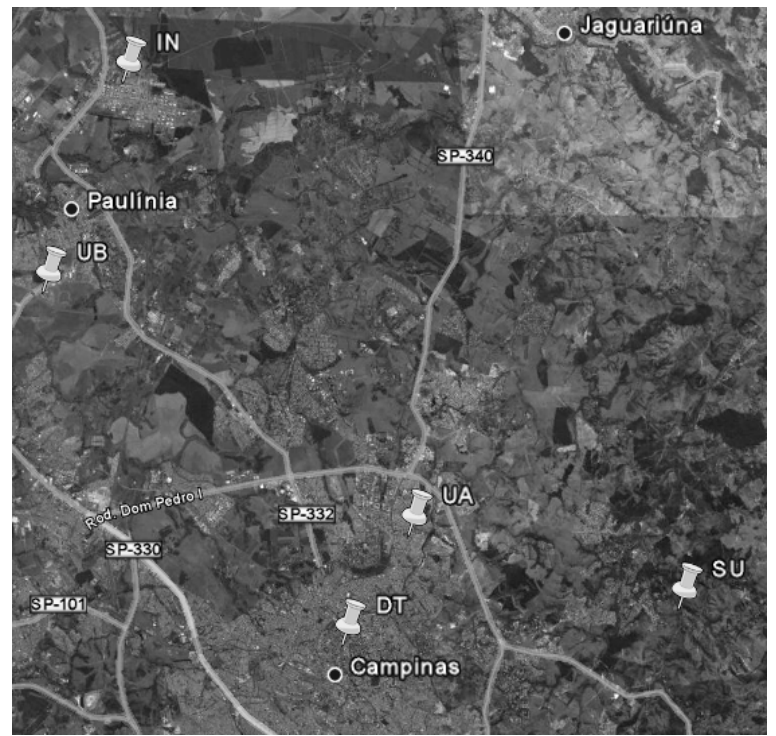

Figure 1: Localization of monitoring sites.

BTEX monitoring occurred between August 2008 and December 2009. Among the five sites monitored the greatest BTEX concentration was found in the industrial site (IN), inside the oil refinery, as expected, once this local represents direct influence of the emissions sources. The lowest concentration was found in site SU, where the intensity of traffic is low and there is no evidence of direct influence of emission sources. In all studied sites the compound found in abundance was toluene, corresponding, at least, to $44 \%$ of total BTEX. Data are presented in Table 4.

Table 4: $\quad$ BTEX average concentrations for all monitoring period.

\begin{tabular}{|c|c|c|c|c|c|}
\hline \multirow[b]{3}{*}{ Pollutant } & \multicolumn{5}{|c|}{ Site } \\
\hline & $\mathrm{SU}$ & DT & UA & UB & IN \\
\hline & $\begin{array}{c}\mathrm{c} \\
\left(\mu \mathrm{g} \mathrm{m}^{-3}\right)\end{array}$ & $\begin{array}{c}c \\
\left(\mu \mathrm{g} \mathrm{m}^{-3}\right)\end{array}$ & $\begin{array}{c}\mathrm{c} \\
\left(\mu \mathrm{g} \mathrm{m}^{-3}\right)\end{array}$ & $\begin{array}{c}\mathrm{c} \\
\left(\mu \mathrm{g} \mathrm{m}^{-3}\right)\end{array}$ & $\begin{array}{c}c \\
\left(\mu \mathrm{g} \mathrm{m}^{-3}\right)\end{array}$ \\
\hline Benzene & 0.90 & 1.4 & 1.2 & 1.4 & 2.1 \\
\hline Toluene & 2.4 & 6.5 & 3.5 & 5.5 & 10 \\
\hline Ethylbenzene & 0.73 & 1.1 & 0.71 & 1.1 & 1.2 \\
\hline Xylenes & 1.5 & 3.9 & 1.9 & 2.4 & 5.0 \\
\hline
\end{tabular}

It was noticed that concentrations observed in the Autumn-Winter months (April to September) were higher than in the Spring-Summer months (October to March). It is due to greater atmospheric stability in cold seasons; and favorable dispersion conditions are found in hot seasons. BTEX concentrations for studied periods are shown in Table 5. 
Table 5: Total BTEX average concentrations for all periods, for SpringSummer months and for Autumn-Winter months.

\begin{tabular}{|c|c|c|c|c|c|}
\hline & \multicolumn{5}{|c|}{ Site } \\
\hline & SU & DT & UA & UB & IN \\
\hline Period & $\begin{array}{c}\mathrm{c} \\
\left(\mu \mathrm{g} \mathrm{m}^{-3}\right)\end{array}$ & $\begin{array}{c}c \\
\left(\mu \mathrm{g} \mathrm{m}^{-3}\right)\end{array}$ & $\begin{array}{c}\mathrm{c} \\
\left(\mu \mathrm{g} \mathrm{m}^{-3}\right)\end{array}$ & $\begin{array}{c}c \\
\left(\mu \mathrm{g} \mathrm{m}^{-3}\right)\end{array}$ & $\begin{array}{c}\mathrm{c} \\
\left(\mu \mathrm{g} \mathrm{m}^{-3}\right)\end{array}$ \\
\hline All & 5.5 & 13 & 7.3 & 10 & 19 \\
\hline Spring-Summer & 5.7 & 11 & 5.9 & 7.6 & 17 \\
\hline Autumn-Winter & 5.3 & 16 & 9.1 & 14 & 20 \\
\hline
\end{tabular}

Evaluation of $\mathrm{B} / \mathrm{T}$ and $\mathrm{X} / \mathrm{E}$ ratios during different periods also show difference of photochemical reactivities of the compounds involved. During Spring-Summer months, the intensive solar radiation enhances the photochemical reactions, reducing toluene and xylenes concentrations, due to their higher photochemical reactivities. Therefore, under these conditions, B/T ratios are high and $\mathrm{X} / \mathrm{E}$ are low.

According to data in Table $6, \mathrm{~B} / \mathrm{T}$ ratio indicates that emissions in all sites are predominantly from vehicles (values between 0.2 and 0.5 ). Site SU and UA showed $\mathrm{B} / \mathrm{T}$ ratio higher than other sites, although this places present the lowest concentrations of BTEX and show no direct influence of emission sources. This indicates that pollution in those sites is indicative of transport. Other sites showed $\mathrm{B} / \mathrm{T}$ ratios above 0.25 , indicating that these locals also present other sources of pollution rather than vehicular, such as fuel and solvent evaporation, although this one is predominant. Based on this parameter, vehicular predominance is also shown in the industrial site (IN). However, once this is an oil refinery, it presents the basic same profile of BTEX than vehicular emissions.

Table 6: $\quad \mathrm{B} / \mathrm{T}$ and $\mathrm{X} / \mathrm{E}$ ratios for studied periods.

\begin{tabular}{|c|c|c|c|c|c|c|}
\hline \multirow[b]{2}{*}{ Period } & \multirow[b]{2}{*}{ Ratio } & \multicolumn{5}{|c|}{ Site } \\
\hline & & $\mathrm{SU}$ & DT & UA & UB & IN \\
\hline All & & 0.38 & 0.22 & 0.34 & 0.25 & 0.21 \\
\hline Spring-Summer & $\mathrm{B} / \mathrm{T}$ & 0.39 & 0.30 & 0.48 & 0.38 & 0.29 \\
\hline Autumn-Winter & & 0.36 & 0.15 & 0.22 & 0.17 & 0.14 \\
\hline All & & 2.05 & 3.55 & 2.68 & 2.18 & 4.17 \\
\hline Spring-Summer & $\mathrm{X} / \mathrm{E}$ & 1.53 & 3.49 & 2.28 & 1.95 & 3.75 \\
\hline Autumn-Winter & & 2.98 & 3.57 & 3.07 & 2.29 & 4.58 \\
\hline
\end{tabular}

$\mathrm{X} / \mathrm{E}$ ratios are also presented in Table 6 and indicate photochemical aging of the emission plume. As xylenes are more reactive than ethylbenzene, a higher $\mathrm{X} / \mathrm{E}$ ratio represents higher xylenes concentration and, consequently, closeness to emission sources. Sites SU and UA presented X/E lowest values (between 2.0 and 2.5), which, in comparison to other values, represent locals far from direct source influence and compounds emitted by the same emission sources. Site UA showed higher proximity to sources $(X / E=2.68)$ than site $U B(X / E=2.18)$, although the second location presented higher BTEX concentrations. This can be assigned to different sources that influence each site: UB have local sources and 
also receive pollutants by transport from the urban region of Campinas, due to wind direction. On the other hand, sites DT and IN showed greatest X/E ratios, indicating that plume are low photochemically aged, i.e., these locals are nearest to emission sources.

Concentrations found in this work were compared to other references [4-7] as show in Table 7. The results shown in this work agree with value found in other cities around the world. Besides, BTEX concentrations found in Campinas are lower than in São Paulo, and more alike other smaller cities in Europe and also less industrialized ones. This can be attributed to less emission sources, as vehicles and industries, and favorable wind regime in the region, which promotes a good dispersion of atmospheric pollutants. Brazilian cities are also favored by ethanol based fuel, which reduces BTEX emissions, in comparison with European and other Latin American cities.

Table 7: BTEX concentrations, in $\mu \mathrm{g} \mathrm{m}^{-3}$, comparison between this work and other references.

\begin{tabular}{|c|c|c|c|c|c|c|c|c|c|c|c|c|}
\hline $\begin{array}{l}\bar{\Xi} \\
\bar{\Xi} \\
\text { छे } \\
\text { ठ }\end{array}$ & D & 穴 & 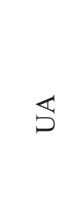 & $\stackrel{m}{\rho}$ & Z & 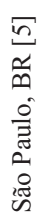 & 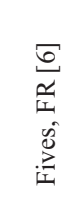 & 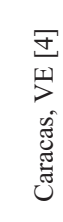 & 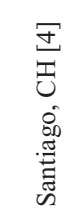 & 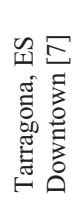 & 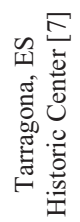 & 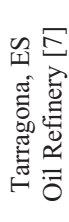 \\
\hline B & 0.90 & 1.4 & 1.2 & 1.4 & 2.1 & 2.0 & 2,72 & 14,2 & 14,8 & 14,3 & 2,2 & 3,3 \\
\hline $\mathrm{T}$ & 2.4 & 6.5 & 3.5 & 5.5 & 10 & 16 & 9,53 & 28,9 & 29,8 & 90,0 & 9,6 & 8,3 \\
\hline E & 0.73 & 1.1 & 0.71 & 1.1 & 1.2 & 4.1 & 1,23 & 5 & 6,5 & 13,9 & 2,9 & 7,0 \\
\hline $\mathrm{m}, \mathrm{p}-\mathrm{X}$ & 0.94 & 2.7 & 1.3 & 1.6 & 3.4 & 7.7 & 3,36 & 16,4 & 25,2 & 40,2 & 7,3 & 4,8 \\
\hline o-X & 0.52 & 1.2 & 0.65 & 0.79 & 1.6 & 2.7 & 1,18 & 5,7 & 8,9 & 14,6 & 1,9 & 8,2 \\
\hline
\end{tabular}

\section{Conclusions}

The study of BTEX concentrations in urban atmosphere and the relations between these compounds are parameters that help us identifying major sources and proximity to them.

Concentrations of major pollutants, as BTEX, in the RMC showed values lower than other Brazilian metropolitan regions, as São Paulo, and other important cities around the world, indicating that there are important contributions by ethanol use as fuel and also by the good dispersion conditions in the region.

$\mathrm{B} / \mathrm{T}$ ratio is also an important indicator of atmospheric pollution from vehicular emissions, which have major importance in urban areas. The evidence of vehicular based pollution may help in the installation of maintenance and prevention programs in order to mitigate emissions. The results obtained for 
RMC showed that all places monitored presented major influence of vehicular pollution.

The study of $\mathrm{X} / \mathrm{E}$ ratios is also important due to its representation of photochemical reaction and proximity to sources. This parameter can be useful in the evaluation of local emission sources and pollution transported from other regions. Industrial site showed that main COV contributions are from sources very close to the monitoring point. On the other hand, suburban site was the most remote location from Campinas urban region, although it presents pollution by transport from other regions upwind, such as São Paulo.

\section{Acknowledgements}

The authors thank Fundação Araucária and Paraná State Government for financial support.

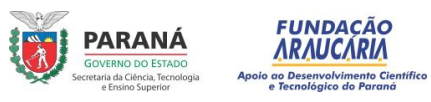

\section{References}

[1] Mallorquí, M.R., Marcé-Recasens, R.M., Borrul-Ballarín, F. Determination of volatile organic compounds in urban and industrial air from Tarragona by thermal desorption and gas chromatography-mass spectrometry. Talanta, 72(3), pp. 941-950, 2007.

[2] Monod, A., Sive, B.C., Avino, P., Chen, T., Blake, D.R., Rowland, F.S. Monoaromatic compounds in ambient air of various cities: a focus on correlations between the xylenes and ethylbenzene. Atmospheric Environment, 35(1), pp. 135-149, 2001.

[3] Lee, S.C., Chiu, M.Y., Ho, K.F., Zou, S.C., Wang, X. Volatile organic compounds (VOCs) in urban atmosphere of Hong Kong. Chemosphere, 48(3), pp. 375-382, 2002.

[4] Gee, I.L., Sollars, C.J. Ambient air levels of volatile organic compounds in latin american and asian cities. Chesmophere, 36(11), pp. 2497-2506, 1998.

[5] Albuquerque, E.L. Volatile organic compounds in urban atmosphere of metropolitan area of São Paulo (PhD Thesis). School of Chemical Engineering, University of Campinas, Brazil, 2009.

[6] Borbon, A., Fontaine H., Locoge, N., Veillerot, M., Galloo, J.C. Developing receptor-oriented methods for non-methane hydrocarbon characterization in urban air - Part I: source identification. Atmospheric Environment, 37(29), pp. 4051-4064, 2003.

[7] Ras, M.R., Borrull, F., Marcé, R.M. Sampling and preconcentration techniques for determination of volatile organic compounds in air samples. Trends in Analytical Chemistry, 28(3), pp. 347-360, 2009. 